\title{
Original Article BREASTFEEDING PRACTICES AMONG WOMEN IN A SELECTED RURAL AREA
}

\author{
M. N. Fahmida Asma', Fouzia Yesmin ${ }^{2}$, Musarrat Haque ${ }^{3}$
}

\begin{abstract}
Background: Breast milk is the only source of nutrition freely available to the newborn from the mother. Breast feeding is the fundamental right of every child. It is the safest, least allergic and best infant feeding method. Absence of breastfeeding significantly increases the risk for a large number of acute and chronic diseases. WHO recommends the practice of exclusive breastfeeding as an essential component of infant nourishment. This present study was conducted to find out the breastfeeding practice among the women of rural areas of Bangladesh.
\end{abstract}

Methods: This cross-sectional type of descriptive study was carried out from October, 2015 to April, 2016 in Kaliakair Upazila under the district of Gajipur. Seven hundred and eighty mothers having children between 6-24 months' age group were interviewed. Data were collected by face-to-face interview with the respondents through a pretested semi structured questionnaire. The study place was selected conveniently and the sampling technique was purposive type of non-probability sampling.

Results: The mean age of the respondents was $24( \pm 4.493)$ years and the mean age of the children was $16.84( \pm 5.766)$ months. The majority (44\%) of the respondents belonged to the education level of class VI-X. Most (93.6\%) of the respondents were housewives. Around two-third (63.9\%) of the mothers were from nuclear families while one-third $(36.1 \%)$ were from joint families. Majority $(55.4 \%)$ of the respondents were from middle income group (10,00130,000 Tk. monthly income). Among all, $91 \%$ had knowledge about the importance of breastfeeding. Most (98.8\%) of the mothers breastfed their babies. Among the breastfed mothers, 55.6\% practiced exclusive breastfeeding. And colostrum was given by $95.5 \%$ mothers. Lack of knowledge and superstition was the main causes not proving colostrum. Breastfeeding was started right after birth by $73.7 \%$ mothers while $24.3 \%$ started within 5 days. More than half of the mothers continued to breastfeed beyond 16 months. Among the mother without exclusive breastfeeding, 44.4\% gave various types of additional food to their babies including powder milk (57\%), cow's milk, shuji, water and some other food, the main reason for giving additional food was insufficiency of breast milk (82.2\%). Most $(90.6 \%)$ of the mothers started complimentary feeding between 6-10 months of age.

Conclusion: In depth community based epidemiological studies may be carried out by covering the whole population to explore the situation in detail.

JOPSOM 2020; 39(2): 50-58

https://doi.org/10.3329/jopsom.v39i2.53166

Keywords: Breastfeeding, Practice, Rural Area.

1. Associate Professor, Department of Community Medicine, Shaheed Suhrawardy Medical Collage

2. Associate Professor, Department of Community Medicine, Shaheed Suhrawardy Medical Collage

3. Professor \& Head, Department of Community Medicine, Shaheed Suhrawardy Medical Collage

Correspondence: M. N. Fahmida Asma._E-mail: fahmida_asma@yahoo.com

\section{INTRODUCTION}

Breast feeding is the fundamental right of every child. Breast milk is the only source of nutrition freely available to the newborn from the mother. ${ }^{1}$ It is the natural first food for babies. It continues to provide up to half or more of the child's nutritional needs during the second half of the first year, and up to one third during the second year of life. Breast feeding is the safest, least allergic and best infant feeding method. It has nutritional, immunological, behavioral and economic benefits and also provide desirable mother infant bonding. ${ }^{2}$

WHO recommends the practice of exclusive breastfeeding as an essential component of infant nourishment, which is defined as giving no food or 
liquid other than mother's breast milk during the first 6 months after birth. ${ }^{3}$

According to the American Academy of Pediatrics, breastfeeding provides advantages with regard to general health, growth, and development. Absence of breastfeeding significantly increases the risk for a large number of acute and chronic diseases including lower respiratory infection, ear infections, bacteremia, bacterial meningitis, urinary tract infection, and necrotizing enterocolitis. Breastfeeding possibly has protective effect against sudden infant death syndrome, Insulin-dependent diabetes mellitus, Crohn's disease, ulcerative colitis, lymphoma, allergic diseases, digestive diseases, and a possible enhancement of cognitive development. ${ }^{4}$

Recent scientific evidence reveals that malnutrition has been responsible, directly or indirectly, for $60 \%$ of all deaths among under five children annually. Over two-third of these deaths are associated with inappropriate feeding practices and occur during the first year of life. ${ }^{5}$ Only $35 \%$ of infants world-wide are exclusively breastfed during the first four months of life and complementary feeding begins either too early or too late with foods which are often nutritionally inadequate and unsafe. ${ }^{6}$ Poor feeding practices in infancy and early childhood, resulting in malnutrition, contribute to impaired cognitive and social development, poor school performance and reduced productivity in later life. Poor feeding practices are therefore, a major threat to social and economic development as they are among the most serious obstacles to attaining and maintaining health at this important age. ${ }^{7}$

Nevertheless, after many years of continuous efforts by various government and non-government agencies across the world, approximately 1.3 million lives are lost annually because of inadequate exclusive breastfeeding. ${ }^{3}$

In Bangladesh, the updated statistics of breastfeeding practices are scarce. In a community from March to June 1995, a total of 5313 mothers having a live birth within 24 months of data collection were interviewed by well-trained interviewer. Results revealed that only $25 \%$ of the mothers initiated breastfeeding immediately after birth, over one-fifth within 1-5 hours, and 39\% after 5 hours of rest following delivery. ${ }^{5}$

A prospective observational study was conducted on a birth cohort of 1677 infants who were born in slum areas of Dhaka in Bangladesh and followed from birth to 12 months of age. The proportion of infants who were breastfed exclusively was only $6 \%$ at enrollment, increasing to $53 \%$ at 1 month and then gradually declining to $5 \%$ at 6 months of age. Predominant breastfeeding declined from $66 \%$ at enrollment to $4 \%$ at 12 months of age. Very few infants were not breastfed, whereas the proportion of partially breastfed infants increased with age. ${ }^{8}$

A random sample of 1100 lower middle class mothers in Dhaka with infants aged 0-6 months, were interviewed in 1995. Although 99 per cent of mothers fed colostrum within 3 days of delivery, 92 per cent also gave one or more traditional prelacteals, and 68 percent gave postlacteals. ${ }^{9}$

Despite the clear benefits and active promotion of breastfeeding, adherence remains low in many developing countries including Bangladesh. It is estimated that fewer than $40 \%$ of infants younger than 6 months old are exclusively breastfed. ${ }^{10}$ The beneficial effects of breastfeeding depend on breastfeeding initiation, and the age at which the breastfed child is weaned. ${ }^{11}$ Breastfeeding practices vary among different regions and communities. Hence, the studies with these relationships help in orienting the breastfeeding promotional activities for preventing a decline in initiation and duration of breastfeeding practices. ${ }^{12}$ Today worldwide attentions is being given towards the importance of breast milk and exclusive breastfeeding for infants, but we are observing insufficient actions by the governments and NGOs in this regard here in Bangladesh. The reason for this could be the scarcity of information about the practice of exclusive breastfeeding resulting in failure to plan and implement proper actions by the concerned authority.

In the present study, an attempt has been made to find out the breastfeeding practices among mothers in a rural area in Bangladesh. This information will hopefully be a part of a larger statistics comprising other studies on this subject and ultimately help the concerned authority to come up with feasible plans on how to promote exclusive breastfeeding in the community and improve the health status of the children below 2 years in Bangladesh.

\section{METHODS}

This was a cross sectional type of descriptive study where respondents were mothers having children of 624 months' age group. This study was conducted in the village Srifoltoli of Kaliakair upazilla under the district of Gajipur and was carried out from October, 2015 to April, 2016. The study place was selected purposively. The respondents who were permanent inhabitants of the study place, cooperative and mentally sound were selected for the study. All the available mothers having children between 6 to 24 
months of age who were willing to participate in the study were interviewed face to face by a pretested semi structured questionnaire. Within the data collection period, 780 mothers were interviewed. At the end of the day, each questionnaire was checked and necessary analysis was done by computer using SPSS16 version program.

\section{RESULTS}

The age of the respondents varied from the minimum of 15 years to the maximum of 37 years. The mean age was $24( \pm 4.493)$ years. Nearly half of the respondents (340) were in the 20-24 years' age group while about a quarter (212) fell in 25-29 years' age group. About one-tenth (90) were in the 30-34 years. The extremes of age groups included the 15-19 years' age group $(12.6 \%)$ and $35-37$ years' age group $(5.1 \%)$. The mean age of the children was $16.84( \pm 5.766)$ months. About one-third of the children (258) were in the 21-24 months' age group, about a quarter (208) in 16-20 months and nearly one-fifth (161) in 11-15 months while another one-fifth (153) were in 11-15 months' age group (Table 1.). Among the 780 children in the study, the number of male children was $427(54.7 \%)$ and female children was 353(45.3\%) whereas $73.8 \%$ (576) were Muslim and 26.2\% (204) were Hindu. Out of 780 respondents, $7.6 \%$ (59) were illiterate, $9.4 \%$ (73) could sign their name only, $18.1 \%$ (141) studied up to class V, 44\% (343) up to class X, $13.5 \%$ (105) completed SSC, $3.5 \%$ (27) completed HSC, $2.7 \%$ (21) were graduate while $1.4 \%$ (11) were post graduate. On the other hand, $8.2 \%$ (64) of the respondents' husbands were completely illiterate, $5.9 \%$ (46) could sign their name only, $15.3 \%$ (119) studied up to class $\mathrm{V}, 31.7 \%$ (247) up to class X, $22.1 \%$ (172) completed
SSC, $11.2 \%$ (87) completed HSC, and $4.1 \%$ (32) were graduate while $1.7 \%$ (13) were post graduate.

Most $(93.6 \%)$ of the respondents were housewives, $4.1 \%$ (32) were service holders, $1.5 \%$ (12) used to do business of different kinds and $0.8 \%$ (6) had other occupation. About one-third (254) of the respondents said their husbands were service holders and another one-third (244) said their husbands were businessman. The rest $13.7 \%$ informed that their husbands were farmer and $22.4 \%$ said that they had some other occupation (22.4\%). About two-third (498) of the respondents belonged to nuclear families and the rest one-third (282) were from joint families. The number of family members of the respondents in this study ranges from 3 to 16 . Mean number of family members is $5.33( \pm 2.458)$. Among the 780 families, almost half (379) had 4 or less number of family members while $43.3 \%$ (338) had 5 to 9 members in the family. Sixtythree $(8.1 \%)$ families had 10 or more members. The monthly family income of the study population ranged between a minimum of Tk. 1,000 and a maximum of Tk. 3,00,000. Mean income was $15380.77 \mathrm{Tk}$. with a standard deviation of \pm 13593.179 . When the families were categorized on the basis of their monthly income, it was found out that almost half of them (432) had a monthly income of 10001 to 30000 Tk. About 39\% (309) had a monthly income of Tk. 10000 or less while $5 \%$ (39) had a monthly income of 30001 or more (Tab.1). Among the 780 families, 21.7\% (169) lived in kacha houses, $66.8 \%$ (521) in semi-pucca houses and $11.5 \%$ (90) lived in pucca houses while $90.5 \%$ (706) of them used sanitary latrines and remaining 9.5\% (74) used non- sanitary latrine. A vast majority of respondents i.e. $91.3 \%$ (712) drank water form tube wells. Only $8.1 \%$ (67) drank from other source e.g. motor pumps while $0.1 \%$ (1) drank from well (Tab. 1).

Tab. 1. Socio-demographic characteristics of respondents

\begin{tabular}{lcc}
\hline $\begin{array}{l}\text { Socio-demographic } \\
\text { Characteristics }\end{array}$ & Frequency & Percentage (\%) \\
\hline Age of the respondents & & \\
\hline 15-19 years & 98 & 12.6 \\
20-24 years & 340 & 43.6 \\
$25-29$ years & 212 & 27.2 \\
$30-34$ years & 90 & 11.5 \\
$35-37$ years & 40 & 5.1 \\
Mean $( \pm$ SD) & $24( \pm 4.493)$ & \\
\hline Age of the children & & \\
\hline
\end{tabular}




\begin{tabular}{|c|c|c|}
\hline 6-10 months & 153 & 19.6 \\
\hline 11-15 months & 161 & 20.6 \\
\hline $16-20$ months & 208 & 26.7 \\
\hline 21-24 months & 258 & \multirow{2}{*}{33.1} \\
\hline $\operatorname{Mean}( \pm \mathrm{SD})$ & $16.84( \pm 5.766)$ & \\
\hline \multicolumn{3}{|c|}{ Gender of the children } \\
\hline Male & 427 & 54.7 \\
\hline Female & 353 & 45.3 \\
\hline \multicolumn{3}{|l|}{ Religion } \\
\hline Islam & 576 & 73.8 \\
\hline Hinduism & 204 & 26.2 \\
\hline \multicolumn{3}{|c|}{$\begin{array}{l}\text { Level of education of the } \\
\text { respondents }\end{array}$} \\
\hline Illiterate & 59 & 7.6 \\
\hline Can sign only & 73 & 9.4 \\
\hline Class I-V & 141 & 18.1 \\
\hline Class VI-X & 343 & 44 \\
\hline SSC & 105 & 13.5 \\
\hline HSC & 27 & 3.5 \\
\hline Graduate & 21 & 2.7 \\
\hline Post-graduate & 11 & 1.4 \\
\hline \multicolumn{3}{|c|}{ Level of education of father } \\
\hline Illiterate & 64 & 8.2 \\
\hline Can sign only & 46 & 5.9 \\
\hline Class I-V & 119 & 15.3 \\
\hline Class VI-X & 247 & 31.7 \\
\hline SSC & 172 & 22.1 \\
\hline HSC & 87 & 11.2 \\
\hline Graduate & 32 & 4.1 \\
\hline Post-graduate & 13 & 1.7 \\
\hline \multicolumn{3}{|c|}{ Occupation of the respondents } \\
\hline Housewife & 730 & 93.6 \\
\hline Service holder & 32 & 4.1 \\
\hline Business women & 12 & 1.5 \\
\hline Others & 6 & 0.8 \\
\hline \multicolumn{3}{|c|}{ Occupation of father } \\
\hline Service holder & 254 & 32.6 \\
\hline
\end{tabular}




\begin{tabular}{lcc} 
Businessman & 244 & 31.3 \\
Farming & 107 & 13.7 \\
Others & 175 & 22.4 \\
\hline Type of family & 498 & 63.9 \\
\hline Nuclear & 282 & 36.1 \\
Joint & & \\
\hline Number of family members & 379 & 48.6 \\
\hline 4or less & 338 & 43.3 \\
5-9 & 63 & 8.1 \\
11 and above & $5.33( \pm 2.458)$ & \\
Mean( \pm SD) & & 39.6 \\
\hline Monthly family income & 309 & 55.4 \\
\hline Tk.10,000 or less & 432 & 5.0 \\
Tk.10,001-Tk.30,000 & 39 & \\
Tk.30,001 or more & & 91.1 \\
\hline Housing & 169 & 11.5 \\
\hline Kacha & 90.5 \\
Pucca & 712 & 66.8 \\
Semi-pucca & 521 & \\
\hline Source of drinking water & & \\
\hline Tube well & & \\
Well & & \\
Others (motor pumps) & & \\
\hline Type of sanitation & & \\
\hline Sanitary latrine & & \\
Non-sanitary latrine & & \\
\hline & & \\
\hline
\end{tabular}

The study revealed that $90.9 \%$ (709) of the respondents had the knowledge about breastfeeding and its usefulness while only $9.1 \%$ (71) had no knowledge about breastfeeding (Fig.1). Out Of the 780 respondents enrolled in this study, Majority (98.8\%) said that they breastfed their babies while only $1.2 \%$ (9) said that they didn't breastfeed their children ever (Fig.2).

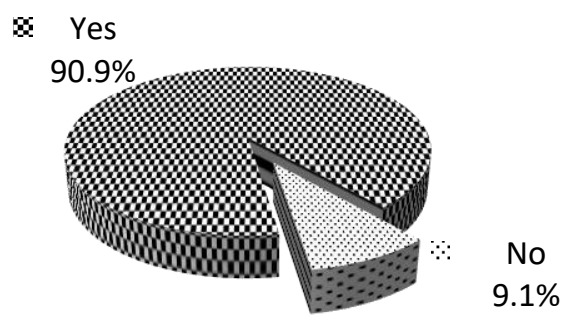

Fig. 1: Distribution of the respondents by knowledge of breastfeeding 
Yes

$98.8 \%$

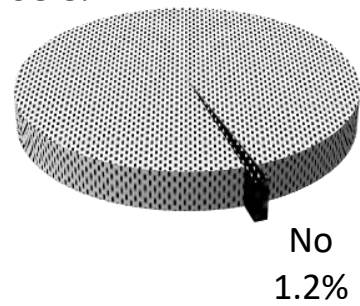

Fig. 2: Distribution of the respondents by practice of breastfeeding

Among the 771 respondents who breastfed their children $95.5 \%$ (736) had given colostrum to their babies and $4.5 \%$ (35) did not (fig.3). The 35 respondents who did not give colostrum to their babies after birth, $34.3 \%$ (12) said that they didn't give it due to superstitions, $48.6 \%$ (17) did not due to lack of knowledge while $17.1 \%$ (6) did not due to other causes i.e. illness of the mother or not being advised by the doctor (Fig.4).

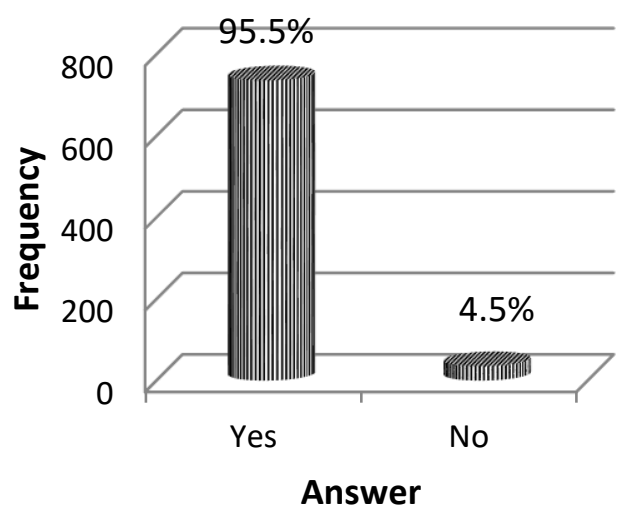

Fig. 3: Distribution of the respondents by giving colostrum to their children

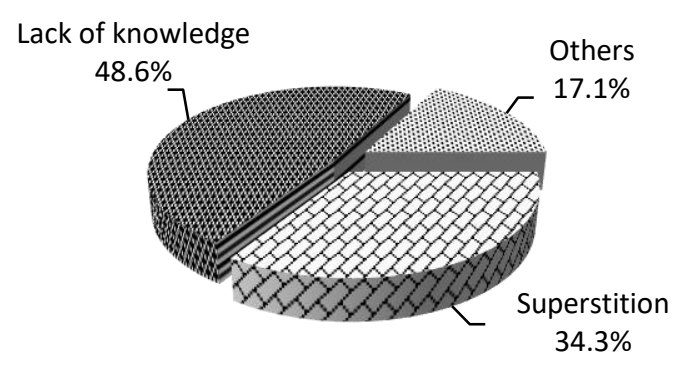

Fig. 4: Distribution of respondents by the reason for not giving colostrum to the child
The time of starting breastfeeding, among the 771 respondents who breastfed their children ranges from 0 day to 15 days after birth with a mean of 0.66 day after birth ( \pm 1.530$)$. Among them, almost three-fourth (568) initiated breastfeeding just after birth while the another one-fourth (187) initiated within 5 days. Only $1.7 \%$ (13) of them initiated breastfeeding between 6 and 10 days and $0.4 \%$ (3) initiated between 11 and 15 days.

The duration of breastfeeding ranges from 1 month to 24 months with a mean duration of 14.87 months and a standard deviation of \pm 6.740 months. Those who breastfed their children, $6.2 \%$ breastfed for 1-5 months, $25.3 \%$ for $6-10$ months, $17.6 \%$ for $11-15$ months, $25.3 \%$ for $16-20$ months and $25.6 \%$ breastfed for 20-24 months.

The study showed that, $44.4 \%$ (342) of the 771 respondents who breastfed their baby did not breastfeed exclusively rather gave additional food during first 6 months while 55.6\% (429) practiced exclusive breastfeeding (Fig.5).

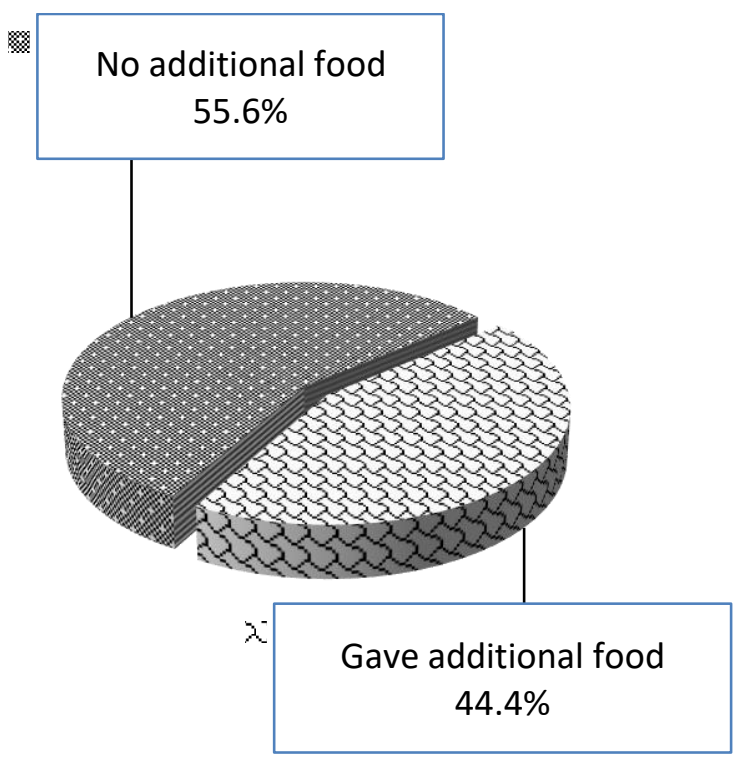

Fig. 5: Distribution of respondents by exclusive breastfeeding

Among those who gave additional food to their children during the first 6 months, it was found that more than half $(57 \%)$ gave powder milk (tin milk) while $14.6 \%$ gave cow's milk, $12.9 \%$ gave shuji, $7.3 \%$ gave water, $1.8 \%$ gave rice powder while $6.4 \%$ gave other food e.g. honey, mustard oil, pora pani etc. (fig.6). 


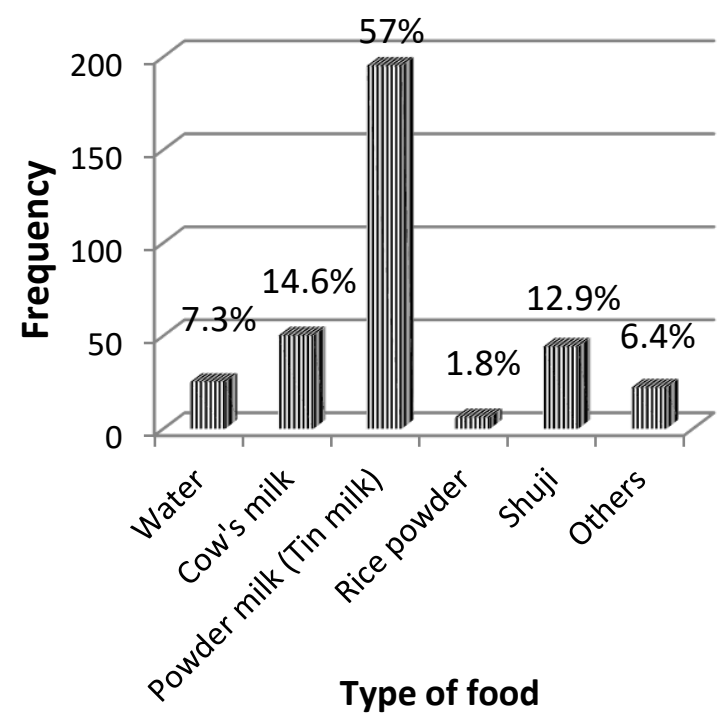

Fig. 6: Distribution of respondents by the type of additional food given during first 6 months

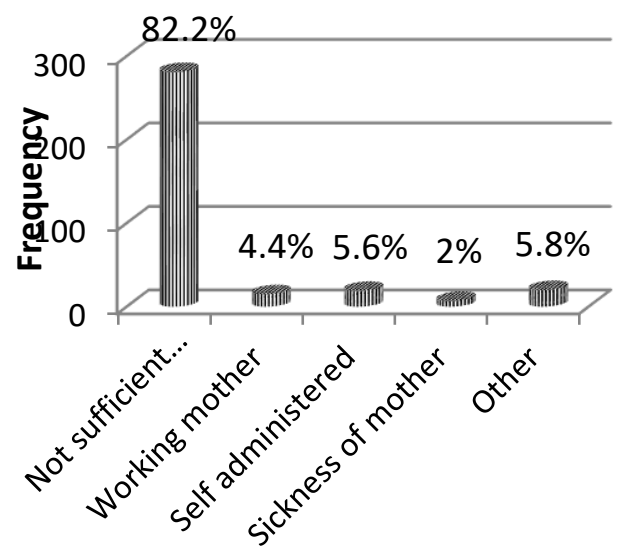

Fig. 7: Distribution of respondents by reasons behind giving additional food

The respondents who gave additional food to their children during first 6 months stated several reasons, $82.2 \%$ (281) gave additional food because of their assumption that sufficient amount of milk was not being produced, $4.4 \%$ were working mothers, $5.6 \%$ self-administered additional food, $2 \%$ gave because of mother's sickness while $5.8 \%$ showed some other reasons e.g. medicines etc. (Fig.7).

Time of starting of complementary feeding among 429 respondents who didn't give any additional food to their children in the first 6 months was 6 months minimum and 15 months' maximum. Mean age of starting was at 6.68 months $(+1.611)$. The respondents who gave additional food during first 6 months, started giving complementary food at 3 months minimum and 22 months' maximum. Mean age of starting was 6.83 months (+1.789). The respondents who did not breastfeed their children, started giving complimentary food at 6 months minimum and 7 months' maximum. Mean age of starting was 6.22 months $( \pm 0.441)$. Among the total 780 respondents, the age of starting complimentary feeding ranged from 3 months to 22 months. The mean age of starting complimentary feeding was 6.74 months $( \pm 1.684)$. Most of the respondents (90.6\%) started complimentary feeding between 6 and 10 months, 5.3\% started between 11 and 15 months, 3.7\% started before 6 months, only $0.3 \%$ started between 16 and 20 months while $0.1 \%$ started after 21 months.

Among the 9 respondents who did not ever breastfeed their children, 4 said it was self-administered, 3 couldn't breastfeed due to sickness and 2 could not because of some other reasons e.g. prescribed by the doctor (Fig.8).

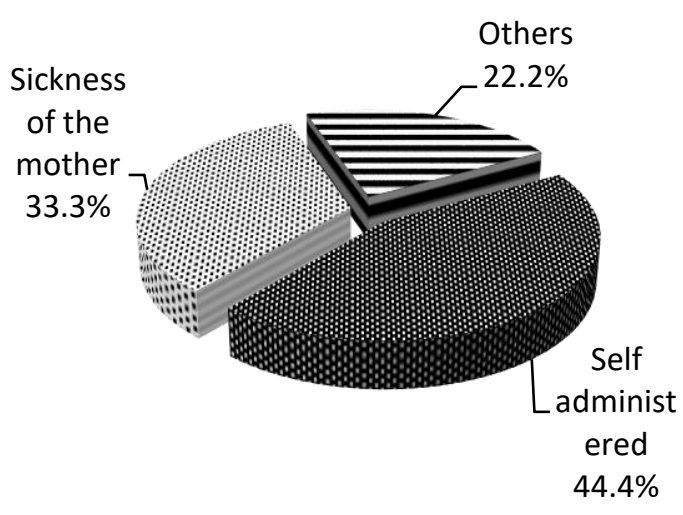

Fig. 8: Distribution of the respondents by reason behind not breastfeeding the child

\section{DISCUSSION}

The present cross sectional type of descriptive study was carried out among the mothers having child between 6-24 months of age of Kaliakair Upazilla under the district of Gajipur. The study was carried out to figure out the practice of breastfeeding among the women of rural area of Bangladesh.

Study revealed, among the 780 mothers, the mean age was 24 years $( \pm 4.493)$ while maximum (nearly half) of the mothers were between 25-29 years of age. The mean age of the children in the study was 16.84 months ( \pm 5.766$)$. Nearly $60 \%$ of the children fell between 16-24 months of age. Mothers of male child 
were $54.7 \%$ of the total while mother of female child were $45.3 \%$. Most of the families $(63.8 \%)$ were nuclear while $36.2 \%$ were joint families.

The study revealed that $92.5 \%$ of the respondents had different levels of education and their husbands also showed a similar percentage $(91.8 \%)$. In both cases, highest percentage of the respondents and their husbands had an education level of class VI-X (44\% respondents and $31.7 \%$ husbands). The literacy rate found here is quite satisfactory given that $52 \%$ of the mothers were found to be illiterate in a rural community in India in 2006 and also housewifery was found to be main occupation of the rural women in 2011. ${ }^{1}$ The mean number of the family members was $5.33( \pm 2.458)$. Most of the families had 5-9 members or less than 4 members $(43.3 \%$ and $48.6 \%$ respectively). The study showed that the average monthly income of the families was $15380.77 \mathrm{Tk}$. $( \pm 13593.179)$. Almost half $(55.4 \%)$ families fell in middle class income group. A small percentage of the families $(5 \%)$ had a monthly income of more than $30000 \mathrm{Tk}$.

Most of the respondents lived in semi pucca houses $(66.8 \%)$ while $21.7 \%$ lived in kacha houses and the rest $11.5 \%$ lived in pucca houses. The sanitation status among the people was unexpected. It was found that $9.5 \%$ of the respondents said that they still used nonsanitary latrine and $90.5 \%$ said that they used sanitary latrine. The study revealed that the vast majority $(91.3 \%)$ of the respondents drank water from the tube well. Only $8.1 \%$ who drank water from other sources mainly used motor pump as the source. In the study it was found that $90.9 \%$ of the mothers had the knowledge about the importance of breastfeeding. This percentage is slightly lower than that found out by Haider et al (1999) in an urban survey in Dhaka, Bangladesh. That study found out $99 \%$ mothers had the knowledge of importance of breastfeeding. But another study states that $67 \%$ of the mothers had breastfeeding education in rural Odissa, India. ${ }^{3}$ Although we saw that $90.9 \%$ of the mothers had the knowledge still $98.8 \%$ of them practiced breastfeeding. So the lack of knowledge didn't seem to pose any significant problem in practicing breastfeeding, be it exclusive or improper breastfeeding. The study revealed that $95.5 \%$ of the mothers gave colostrum to their child. Another study in urban Dhaka, Bangladesh found it $99 \% .^{9}$ So this showed a slight decrease in the percentage which is unsatisfactory given the awareness raising programs of various government and non-government organizations for the past decade.

The mothers, who did not feed their babies colostrum, gave several reasons behind it, the main two reasons being lack of knowledge (48.6\%) and superstition $(34.3 \%)$.

The average time of starting of breastfeeding was 0.66 days after birth $( \pm 1.530)$. Most of the mothers $(73.7 \%)$ started breastfeeding just after birth while $24.3 \%$ started within 5 days. This showed a significant improvement as a study in Bangladesh showed that only $25 \%$ mothers started breastfeeding immediately after birth in a rural community. ${ }^{5}$ The mean duration of breastfeeding was found to be 14.87 months $( \pm 6.470)$ with more than half of the mothers practicing it beyond 16 months of age. The percentage is again a satisfactory one as a study found out only $2 \%$ of the mother's breastfed their babies up to 24 months in a rural community of India in $2014 .{ }^{4}$ But it was also found out that a quarter of the mothers breastfeed their babies not beyond 10 months of age. So we see that there are still a lot of works to be done as far as the awareness of the mothers is concerned.

The study showed that of the 771 respondents who said they breastfed their babies, $55.6 \%$ said they did not give any additional food during the first 6 months of age. So this $55.6 \%$ is the percentage of mothers who practiced exclusive breastfeeding. This percentage shows a significant improvement in the situation as only $15 \%$ of the mothers here practiced exclusive breastfeeding back in $1999 .{ }^{9}$ The percentage is also a lot higher than the $5.13 \%$ mothers who practiced it in rural India in $2012 .^{2}$

When the respondents were inquired about the types of additional food given to children during the first 6 months of life, more than half of the respondents said it was powder milk (Tin milk). This showed a change in the trend as Sundaram et al found out that the most common additional food was animal milk in rural Gaibandha, Bangladesh in 2012. This study showed only $14.6 \%$ of the mothers gave cow's milk to their babies. Other food included honey, mustard oil etc. The mothers mentioned the reasons behind giving additional food was insufficiency of breast milk $(82.2 \%)$. This finding corresponds with the findings of a study in India found $92 \%$ of the mothers in rural India. ${ }^{2}$ The study showed that most of the mothers (90.6\%) started complimentary feeding between 6-10 months. Only 9 respondents had not breastfed their babies at all. The reasons included mother's sickness $(33.3 \%)$, self-administration $(44.4 \%)$ and other causes $(22.2 \%)$. The result is unsatisfactory given the ongoing programs of the government and NGOs to raise awareness among the mothers about the importance of breastfeeding. 


\section{CONCLUSION}

From the present study it can be concluded that most of the respondents $98.8 \%$ (771) breastfed their babies to some extent and only $1.2 \%$ (9) did not breastfed their babies at all. Out of the 771 who did breastfeed, $55.6 \%$ (429) practiced exclusive breastfeeding. Almost 91\% (709) had knowledge about the importance of breastfeeding while $9 \%$ (71) did not. Most of the mothers $95.5 \%$ gave their children colostrum while $4.5 \%$ did not. The main two reasons behind not giving colostrum were lack of knowledge and superstition. Three-fourth of the respondents started breastfeeding right after the birth and 24.3\% within 5 days. The average of duration of breastfeeding was $14.87( \pm 6.740)$ months and more than half of the mothers continued breastfeeding beyond 16 months of age. The mothers, who gave additional food (before 6 months of age) cited insufficiency of breast milk as the main reason $(82.2 \%)$. Powder milk was the main additional food of choice $(57 \%)$. More than $90 \%$ of the mothers started complimentary feeding between 6-10 months of age. The mothers who didn't breastfeed their babies, gave sickness and self-administration as the main causes. A large scale, in depth study is essential to find out the breastfeeding practices in women of rural area throughout the country so that appropriate health education program can be arranged to aware people about the importance exclusive breastfeeding, administration of colostrum and complimentary feeding.

\section{REFERENCES}

1. Senthilvel V, Sumathi S, Singh Z, Jayanthi V. (2011) A study of breast feeding practices among non-working women in rural area of Puducherry. Indian Journal of Maternal and Child Health. Volume 13. Issue 3. P.1-12.

2. Vyas S, Sharma P, Kandpal S D, Semwal J, Srivastava, Nautiyal V (2012). A COMMUNITY BASED STUDY ON BREASTFEEDING PRACTICES IN A RURAL AREA OF UTTARAKHAND. National journal of Community Medicine. Volume-3 Issue 2. P 283

3. Behera D, Kumar K. Predictors of exclusive breastfeeding intention among rural pregnant women in India: a study using theory of planned behavior Rural and Remote Health Volume 15. Issue 3405. (Online) 2015 P. 1

4. Das R, Mukherjee A. (2014) Knowledge, Attitude and Practices of Infant Feeding Practices among Rural Women in Eastern India. Journal of Evolution of Medical and Dental Sciences; Vol. 3, Issue 02, P: 506-512

5. Akhter HH, Akhter M, Azad KM. (1998) A National Baseline Survey to Assess the Breastfeeding Practices in Bangladesh Institute of Research for Promotion of Essential and Reproductive Health and Technologies [BIRPERHT], Feb. xxxviii, 151, [20]

6. http://www.who.int/elena/titles/complementary_f eeding/en/

7. http://www.who.int/elena/titles/exclusive_breastf eeding/en/

8. Arifeen S, Black R E, Antelman G, Baqui A, Caulfield L, Becker S (2001) Exclusive Breastfeeding Reduces Acute Respiratory Infection and Diarrhea Deaths Among Infants in Dhaka Slums. PEDIATRICS Vol. 108, Issue No. 4-October. P.1

9. Haider RAB, Kabira A, Ashworth AB. (1999) News from the region. Are breastfeeding promotion messages influencing mothers in Bangladesh? Results from an urban survey in Dhaka, Bangladesh. Journal of Tropical Pediatrics. Volume 55. Issue 5. P. 315-318.

10. Sundaram ME, Labrique AB, Mehra S, Ali H, Shamim AA, Klemm RDW, West Jr KP, Christian P. (2013) Early Neonatal Feeding Is Common and Associated with Subsequent Breastfeeding Behavior in Rural Bangladesh. The Journal of Nutrition. doi:10.3945/jn.112.170803.

11. http://app.dghs.gov.bd/localhealthBulletin2015/p ublish/publish.php?org=10000141\&year $=2015$

12. Madhu K, Chowdary S, Masthi R. (2009) Breast Feeding Practices and Newborn Care in Rural Areas: A Descriptive Cross-Sectional Study. Indian Journal of Community Medicine. Volume 34. Issue 3. P. 243-246 